\title{
Sistem control pencahayaan pada smart class dengan ESP8266
}

\section{SISTEM PENCAHAYAAN PADA SMART CLASS DENGAN ESP8266}

\author{
Ahmad Fauzi Darmansyah \\ Program Studi Teknik Otomasi Listrik Industri, Jurusan Teknik Elektro, Politeknik Negeri Jakarta, \\ Jl. Prof.Dr.G.A.Siwabessy, Kampus UI, Depok, 16425 \\ Email : ahmadfauzid@gmail.com,
}

\begin{abstract}
Optimal lighting in the Smart Class can support the learning process for the better because students' eyes become comfortable. In accordance with SNI 03-6575-2001 classroom lighting is 250 lux. Based on the measurement of lighting levels on the 2nd floor Electric Laboratory smart class, the average morning and afternoon lighting is 160 lux. This value is not in accordance with SNI standards. So in this research a lighting control system was made using ESP8266 as a controller, BH1750 sensor as a light sensor and dimmer module as additional lights to increase or decrease the lighting level. This system automatically adjusts the lighting level with a set value of 250 lux. The result is that the lighting control system can function properly with the lighting level adjustment time to set point being 25 to 30 seconds.
\end{abstract}

Keywords: smart class, lighting control, ESP8266, BH1750, Dimmer Module

\begin{abstract}
ABSTRAK
Pencahayaan yang optimal pada Smart Class dapat mendukung proses pembelajaran menjadi lebih baik karena mata mahasiswa menjadi nyaman. Sesuai standar SNI 03-6575-2001 pencahayaan ruang kelas adalah 250 lux. Berdasarkan pengukuran level pencahayaan pada smartclass laboratorium Listrik lantai 2, rata-rata pencahayaan pagi dan siang hari adalah 160 lux. Nilai ini belum sesuai dengan standar SNI. sehingga pada penelitian ini dibuatlah sistem kontrol pencahayaan dengan menggunakan ESP8266 sebagai kontroller, sensor BH1750 sebagai sensor cahaya dan dimmer module sebagai lampu tambahan untuk menambah atau mengurangi level pencahayaan. Sistem ini otomatis melakukan penyesesuaian level pencahayaan dengan nilai set point 250 lux. Hasilnya sistem control pencahayaan dapat berfungsi dengan baik dengan waktu penyesuaian level pencahayaan ke set point adalah 25 sampai 30 detik.
\end{abstract}

Kata Kunci: Smart class, kontrol Pencahayaan, ESP8266, BH1750, Dimmer Module

\section{PENDAHULUAN}

Smart Class merupakan ruangan kelas yang ditingkatkan secara teknologi dan elektronik agar dapat menunjang proses belajar mengajar. Salah satu teknologi yang digunakan adalah sistem pencahayaan ruangan otomatis. Manfaatnya adalah pencahayaan pada ruangan kelas tersebut akan selalu optimal dan sesuai standar yang ada. Standar pencahayaan pada ruangan kelas berdasarkan standar SNI 03-65752001 yaitu 250 Lux [1]. Jika melebihi atau kurang dari angka tersebut maka akan berdampak pada kerusakan mata dan kenyamanan mahasiswa saat belajar.

Dengan manfaat tersebut, maka sistem pencahayaan ruangan otomatis akan diterapkan pada smart class Laboratorium Teknik Listrik Lantai 2 Politeknik Negeri Jakarta. Kondisi pencahayaan pada ruangan tersebut di pagi dan 


\section{Sistem control pencahayaan pada smart class dengan ESP8266}

siang hari sekitar 190 Lux. Nilai ini belum sesuai dengan standar SNI. Sehingga pada penelitian ini dibuat sistem kontrol pencahayaan dengan menggunakan mikrokontroler ESP8266 sebagai pengendali, sensor BH1750 sebagai pendeteksi cahaya, dan modul dimmer sebagai lampu tambahan untuk menambah atau mengurangi level pencahayaan.

Penelitian tentang sistem kontrol pencahayaan lampu dengan mikrokontroler ESP8266 telah diaplikasikan antara lain pada smarthome [2-5] dan ruangan berjendela [6, 7] namun penelitian ini hanya sebatas on-off lampu saja. Sedangkan sistem kontrol pencahayaan yang dibuat dalam penelitian ini memiliki keunggulan yaitu sistem dapat melakukan adjustment secara otomatis apabila pencahayaan dalam ruangan belum mencapai standar yang ditentukan.

\section{METODE PENELITIAN}

\subsection{Diagram blok}

Realisasi keseluruhan sistem sesuai dengan diagram blok sistem (Gambar 1) dan mengacu pada flowchart (Gambar 2).

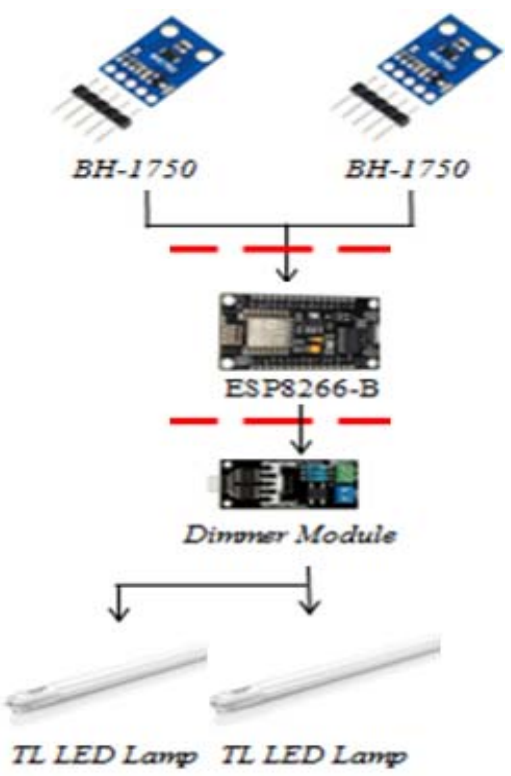

Gambar 1. Diagram blok sistem

Keterangan Gambar 1

BH-1750 : Sensor cahaya sebagai feedback pembacaan nilai level pencahayaan untuk kontroler.

ESP8266 : Mikrokontroler sebagai otak sistem yang akan memproses input sistem agar mencapai set poin yang ditentukan.
Dimmer : interface untuk mengatur module pencahayaan atas perintah kontroler.

Lampu : Lampu tambahan yang

TL terhubung dengan dimmer

\subsection{Rancangan Alat}

Sistem kontrol pencahayaan dipasang pada smart class laboratorium teknik listrik lantai 2. Kerja sistem ini terdiri dari mode manual dan otomatis. Pemilihan mode dilakukan melalui aplikasi web. Kondisi manual dipergunakan jika sistem mengalami gangguan atau perlu perawatan. Sedangkan kondisi automatis merupakan default sistem. Sensor cahaya akan bekerja secara kontinyu untuk mendeteksi perubahan cahaya. Jika terjadi perubahan cahaya maka sensor akan mengirimkan sinyal kepada kontroler untuk memproses kondisi ini. Lalu kontroler mengirimkan sinya ke dimmer module untuk melakukan adjustment sampai cahaya sesuai dengan set point. Flowchart sistem kontrol pencahayaan terlihat pada Gambar 2 .

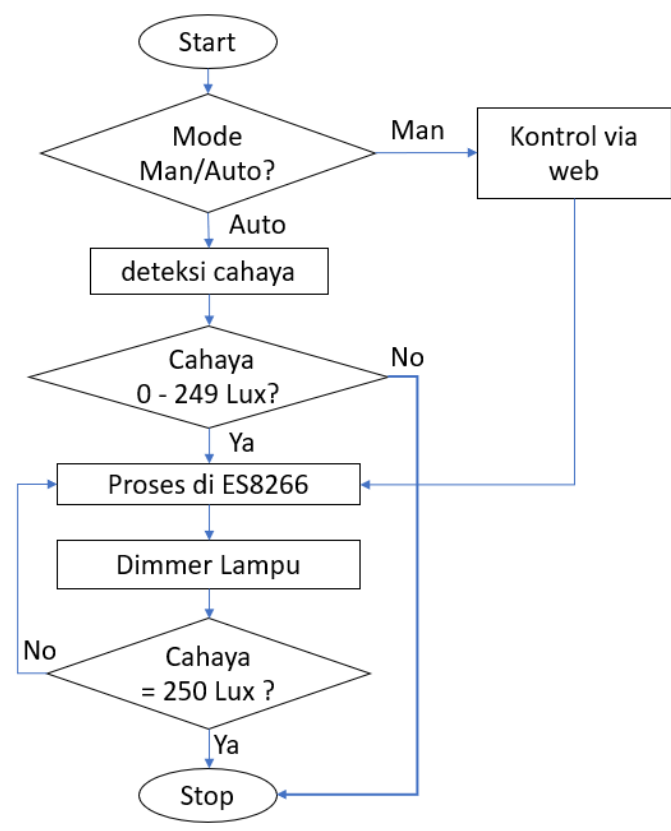

Gambar 2. Flowchart sistem kontrol pencahayaan

\section{HASIL dan PEMBAHASAN}

\subsection{Pengujian fungsi sistem}

Semua komponen pada sistem kontrol pencahayaan smart class diuji fungsinya dengan dua cara, yaitu pengujian tanpa tegangan dan dengan tegangan. Pengujian tanpa tegangan bertujuan untuk mengetahui instalasi sistem 


\section{Sistem control pencahayaan pada smart class dengan ESP8266}

sudah tersambung dengan benar atau belum. Hasil pengujian pada Tabel 1 .

Tabel 1. Data pengujian tanpa tegangan

\begin{tabular}{|c|c|c|c|}
\hline $\begin{array}{c}\text { Nama } \\
\text { Komponen }\end{array}$ & Dari Pin & Ke Pin & Ket \\
\hline \multirow{4}{*}{ ESP8266 } & Vin & $\begin{array}{c}\text { Power Supply } \\
5 \mathrm{~V}+\end{array}$ & Ok \\
\hline & Ground & $\begin{array}{c}\text { Power Supply } \\
5 \mathrm{~V}-\end{array}$ & $\mathrm{Ok}$ \\
\hline & 13 & $\begin{array}{l}\text { ZC Dimmer } \\
\text { Module }\end{array}$ & $\mathrm{Ok}$ \\
\hline & 15 & $\begin{array}{l}\text { PWM Dimmer } \\
\text { Module }\end{array}$ & Ok \\
\hline \multirow{5}{*}{ BH1750-A } & Vin & $\begin{array}{c}\text { Power Supply } \\
5 \mathrm{~V}+\end{array}$ & $\mathrm{Ok}$ \\
\hline & Ground & $\begin{array}{c}\text { Power Supply } \\
5 \mathrm{~V}-\end{array}$ & $\mathrm{Ok}$ \\
\hline & SDA & 4 ESP8266-B & Ok \\
\hline & SCL & 0 ESP8266-B & Ok \\
\hline & ADDR & $\begin{array}{c}\text { Power Supply } \\
5 \mathrm{~V}+\end{array}$ & Ok \\
\hline \multirow{5}{*}{ BH1750-B } & Vin & $\begin{array}{c}\text { Power Supply } \\
5 \mathrm{~V}+\end{array}$ & Ok \\
\hline & Ground & $\begin{array}{c}\text { Power Supply } \\
\text { 5V - }\end{array}$ & $\mathrm{Ok}$ \\
\hline & SDA & 4 ESP8266-B & Ok \\
\hline & SCL & 0 ESP8266-B & Ok \\
\hline & ADDR & - & - \\
\hline \multirow{10}{*}{$\begin{array}{l}\text { Dimmer } \\
\text { Module }\end{array}$} & Vin & $\begin{array}{c}\text { Power Supply } \\
5 \mathrm{~V}+\end{array}$ & Ok \\
\hline & Ground & $\begin{array}{c}\text { Power Supply } \\
5 \mathrm{~V}-\end{array}$ & Ok \\
\hline & $\mathrm{ZC}$ & 13 ESP8266-B & Ok \\
\hline & PWM & 15 ESP8266-B & Ok \\
\hline & $\mathrm{IN} \mathrm{AC} \mathrm{+}$ & MCB 1 & Ok \\
\hline & IN AC - & Sumber Netral & Ok \\
\hline & LOAD & Lampu & Ok \\
\hline & $\mathrm{AC}+$ & 1 dan 2 & \\
\hline & LOAD & Lampu & $\mathrm{Ok}$ \\
\hline & $\mathrm{AC}-$ & 1 dan 2 & \\
\hline \multirow{2}{*}{ Lampu 1} & Fasa & $\begin{array}{l}\text { LOAD AC + } \\
\text { Dimmer } \\
\text { Module }\end{array}$ & Ok \\
\hline & Netral & $\begin{array}{l}\text { LOAD AC - } \\
\text { Dimmer } \\
\text { Module }\end{array}$ & Ok \\
\hline \multirow{2}{*}{ Lampu 2} & Fasa & $\begin{array}{l}\text { LOAD AC + } \\
\text { Dimmer } \\
\text { Module }\end{array}$ & Ok \\
\hline & Netral & $\begin{array}{l}\text { LOAD AC - } \\
\text { Dimmer } \\
\text { Module }\end{array}$ & Ok \\
\hline
\end{tabular}

Berdasarkan Tabel 1, semua komponen sudah tersambung dengan baik pada pin I/O yang telah ditentukan. Hal ini terlihat pada keterangan "Ok" yang menandakan bahwa komponen tersambung dengan baik.

Sedangkan pengujian dengan tegangan bertujuan untuk mengetahui apakah komponen dapat dipakai pada tegangan normalnya. Hasil pengujian pada Tabel 2 .

Tabel 2. Data pengujian dengan tegangan pada komponen sistem kontrol pencahayaan

\begin{tabular}{lccl}
\hline \multicolumn{1}{c}{$\begin{array}{c}\text { Nama } \\
\text { Komponen }\end{array}$} & \multicolumn{2}{c}{ Tegangan } & \\
& ON & OFF & Keterangan \\
\hline ESP8266-B & 5 & 0 & Sesuai \\
BH1750-A & 5 & 0 & Sesuai \\
BH1750-B & 5 & 0 & Sesuai \\
Dimmer Module & 5 & 0 & Sesuai \\
Lampu 1 & 220 & 0 & Sesuai \\
Lampu 2 & 220 & 0 & Sesuai \\
\hline
\end{tabular}

Pada Tabel 2 terlihat bahwa masing-masing komponen sudah On pada tegangan normalnya. Hal ini menandakan bahwa komponen berfungsi dengan baik dan siap dioperasikan.

3.2 Pengujian Tingkat Pencahayaan

Tingkat pencahayaan pada ruangan smart class diukur menggunakan lux meter. pengukuran dilakukan pada jam belajar pukul 07.30 - 15.30 WIB selama dua hari.

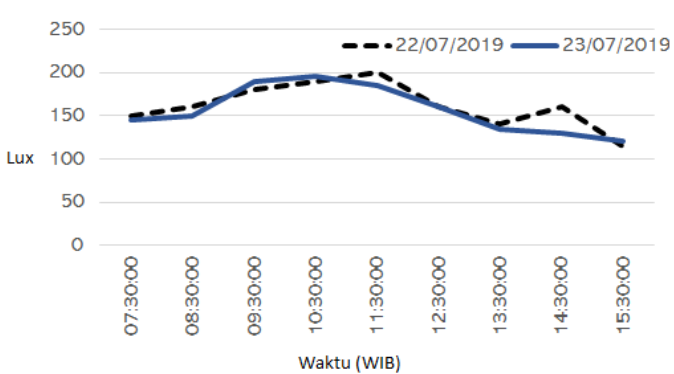

Gambar 3. Pengukuran tingkat pencahayaan pada smart class pukul 07.30 - 15.30 WIB pada tanggal 22 - 23 Juli 2019

Berdasarkan Gambar 3, tingkat pencahayaan pada smart class berada pada nilai $150-200$ lux. Nilai ini belum sesuai dengan standar SNI untuk ruang kelas.

Nilai tingkat pencahayaan ini dibaca oleh sensor cahaya lalu diteruskan ke mikrokontroler. mikon akan memberikan sinyal PWM kepada aktuator dalam hal ini adalah dimmer modul untuk menyalakan lampu sesuai kebutuhan. Jika pembacaan sensor 150 lux maka ESP8266 akan memproses kekurangan cahaya sebesar 100 lux. ESP8266 memberikan sinyal PWM dengan duty cyle $40 \%$ atau tegangan sebesar 2 Volt pada 


\section{Sistem control pencahayaan pada smart class dengan ESP8266}

dimmer modul untuk menyalakan lampu sebesar 88 Volt, seperti terlihat pada Tabel 3.

Tabel 3. Data adjustment level pencahayaan

\begin{tabular}{crccc}
\hline $\begin{array}{c}\text { pengukuran } \\
\text { intensitas } \\
\text { cahaya } \\
\text { (lux) }\end{array}$ & $\begin{array}{c}\text { Adjust- } \\
\text { ment } \\
\text { (lux) }\end{array}$ & $\begin{array}{c}\text { PWM } \\
\text { (V) }\end{array}$ & $\begin{array}{c}\text { Teg } \\
\text { Lampu } \\
\text { (V) }\end{array}$ & $\begin{array}{c}\text { Waktu } \\
\text { mencapai } \\
\text { set point } \\
\text { (detik) }\end{array}$ \\
\hline 150 & 100 & 2.00 & 88.0 & 27 \\
160 & 90 & 1.80 & 79.2 & 25 \\
180 & 70 & 1.40 & 61.6 & 30 \\
190 & 60 & 1.20 & 52.8 & 25 \\
200 & 50 & 1.00 & 44.0 & 28 \\
160 & 90 & 1.80 & 79.2 & 25 \\
140 & 110 & 2.20 & 96.8 & 27 \\
160 & 90 & 1.80 & 79.2 & 25 \\
115 & 135 & 2.70 & 118 & 25 \\
\hline
\end{tabular}

Berdasarkan Tabel 3, sistem kontrol pencahayaan telah bekerja dengan baik. Hal ini ditandai dengan berfungsinya sensor cahaya dalam mendeteksi level pencahayaan. Data tersebut dikirim ke ESP8266. Kemudian ESP8266 memproses selisih yeng terjadi antara set point dengan nilai pembacaan sensor dan melakukan adjustment. Waktu yang diperlukan sistem untuk mencapai set point paling cepat adalah 25 detik dan paling lama adalah 30 detik.

\section{KESIMPULAN}

Berdasarkan beberapa percobaan yang telah dilakukan, dapat disimpulkan bahwa system kontrol pencahayaan pada smart class laboratorium Teknik listrik berkerja dengan baik. Sistem dapat melakukan adjustment pencahayaan secara otomatis dalam mencapai kondisi pencahayaan yang sesuai standar ruang kelas. Waktu yang diperlukan pada proses ini adalah 25- 28 detik.

\section{DAFTAR PUSTAKA}

[1] SNI 03-6575-2001 Tata Cara Perancangan Sistem Pencahayaan Buatan Pada Bangunan Gedung, 2001.

[2] M. Y. Efendi, "Implementasi Internet of Things Pada Sistem Kendali Lampu Rumah Menggunakan Telegram Messenger Bot Dan Nodemcu Esp 8266," Global Journal of Computer Science Technology, 2019.

[3] A. Listyo, A. Purwanto, and S. Lutfi, "Pengendalian Lampu Rumah Berbasis Google Asisstant Melalui Smartphone
Menggunakan Node MCU-12E ESP8266 Di Nuke Komputer Service," HIMSYATECH, vol. 20, no. 2, 2019.

[4] R. P. Pratama, "Pengendali Lampu Rumah Berbasis Esp8266 Dengan Protokol MQTT," TESLA: Jurnal Teknik Elektro, vol. 22, no. 1, 2020.

[5] M. Dwiyaniti, I. T. Atmaja, Y. Firdaus, and H. Noveansyah, "Pengembangan Multiplatform Pengendali Dan Pemonitor Perangkat Listrik Pada Miniatur Smart Home," Electrices, vol. 1, no. 1, pp. 1-8, 2019.

[6] C. Lubis, K. Novianti, and T. Tony, "Perancangan prototipe sistem penerangan otomatis ruangan berjendela berdasarkan intensitas cahaya," 2012.

[7] L. Hakim, "Rancang bangun sistem pengaturan penerangan ruangan berbasis mikrokontroler," repo.pens.ac.id, pp. 1-8, 2011. 